\title{
Epidemio-Clinical Profile of Skin Conditions in Pediatric Dermatology Consultation of the University Hospital of Treichville
}

\author{
Kouadio Célestin Ahogo ${ }^{1^{*},}$ Kouamé Kanga1, Kouassi Kouamé Alexandre ${ }^{1}$, Allou Ange Sylvain ${ }^{1}$, \\ Enoh Jacob ${ }^{2}$, Balliet Gbiagohi Sandrine ${ }^{1}$
}

${ }^{1}$ Department of Dermatology-Venerology, CHU Treichville, Abidjan, Côte d'Ivoire

${ }^{2}$ Department of Pediatric, CHU Treichville, Abidjan, Côte d'Ivoire

Email: *ahogoceleste@yahoo.fr

How to cite this paper: Ahogo, K.C., Kanga, K., Alexandre, K.K., Sylvain, A.A., Jacob, E. and Sandrine, B.G. (2018) Epidemio-Clinical Profile of Skin Conditions in Pediatric Dermatology Consultation of the University Hospital of Treichville. Journal of Cosmetics, Dermatological Sciences and Applications, 8, 272-277. https://doi.org/10.4236/jcdsa.2018.84029

Received: October 10, 2018

Accepted: December 24, 2018

Published: December 27, 2018

Copyright ( $\odot 2018$ by authors and Scientific Research Publishing Inc. This work is licensed under the Creative Commons Attribution International License (CC BY 4.0).

http://creativecommons.org/licenses/by/4.0/

\section{(c) (i) Open Access}

\begin{abstract}
Introduction: Dermatoses are common in the pediatric population. They have certain particularities such as the prevalence of the diaper dermatitis and genetic disorders. Paediatric dermatological problems are common, with some conditions requiring specialist consultation. Often appropriate diagnosis and therapy are sometime delayed in certain countries. Few studies have focused on pediatric aspects of skin diseases in Côte d'Ivoire. We initiated this work to contribute to a better knowledge of pediatric skin conditions in our work context. Material and Methods: This is a cross-sectional prospective, descriptive and analytical study carried out in the Dermatology Department of the University Hospital of Treichville from January 2015 to December 2017. Data from the study were collected on a survey card that included socio-demographic characteristics and clinical aspects. All children with cutaneous and mucosal disease seen in pediatric dermatology consultation have been taken into account in the study. Results: 11,487 patients were seen in dermatology consultation during the period of our study with only 302 children, a prevalence of $2.6 \%$. The sex ratio was 0.9 . The main reason for consultation was pruritus $(22.65 \%)$. In $63.9 \%$ of the cases the child was referred by a family member whereas more than $1 / 3$ of the children (39.07\%) had previously been consulted by a pediatrician. Among children referred with a skin diagnosis, the half had a correct diagnosis The most prevalent disorders by category were dermatitis (57.9\%) and infections (29.5\%). Multiple diagnosis were made in $9.27 \%$ of the patients. The most common pathologies encountered were prurigo (23.2\%), scabies (12.9\%) and atopic dermatitis (9.6\%). The lesions were mainly located on the head $(23.31 \%)$ and the lower limbs
\end{abstract}


(20.51\%). In almost all cases (99.3\%), the diagnosis was essentially clinical. Conclusion: Pediatric dermatoses are numerous and varied. They are dominated by Prurigo and Scabies. This study invites for close collaboration between pediatricians and dermatologists in order to optimize their therapeutic management. The knowledge of this spectrum of pediatric skin diseases would be useful for future health planning in order to reduce disease burden.

\section{Keywords}

Dermatoses, Children, Côte d'Ivoire

\section{Introduction}

Pediatric dermatoses are cutaneous conditions of children. They are common pathologies in the pediatric population. Indeed, they represent on average $30 \%$ of consultations in pediatric practice [1]. The spectrum of skin disorders seen in a population may reflect the level of hygiene, social development and health status. Pediatric skin conditions have certain particularities such as the prevalence of eruptive fevers and genetic disorders. Some even have a quasi-exclusive pediatric expression such as diaper dermatitis and hemangiomas [2]. Paediatric dermatological problems are common, with some conditions requiring specialist consultation. Often appropriate diagnosis and therapy are delayed because of the lack of specialist in dermatology in some areas and difficulties in referring and access to dermatology services [3]. Pediatric skin conditions have been the subject of several studies in western countries and in North Africa, but few studies have been devoted to the pediatric aspects of skin diseases in Côte d'Ivoire. It was therefore appropriate for us to conduct this study at the Department of Dermatology-venerology of the University Hospital Centre of Treichville. The aim of our work was to describe the epidemio-clinical profile of pediatric skin conditions and to indicate the etiological aspects in Côte d'Ivoire.

\section{Material and Methods}

This is a cross-sectional prospective, descriptive and analytical study carried out in the Dermatology Department of the University Hospital of Treichville were a pediatric dermatology consultation have been created. The study was conducted over a 2-year period from January 2015 to December 2017. Have been taken into account and included in the study all children with cutaneous and mucosal diseases seen in pediatric dermatology consultation. The study was approved by the ethic committee of the hospital. Data from the study were collected on a survey card that included socio-demographic characteristics and clinical data such as the sexe, the age, the main symptoms, the duration, the location of the lesion, the type of dermatosis, therapeutic and evolutive aspects. The data was entered and analysed using Microsoft $^{\oplus}$ Excel $^{\oplus} 2010$ software version 14.0.4760.1000. As for 
the analysis of the data, it was made using the software Epi Info 6.4d.

\section{Results}

\subsection{At the Epidemiological Level}

11,487 patients consulted in dermatology department during the period of our study with only 302 children. The prevalence of pediatric dermatoses in consultation was thus $2.6 \%$. The age of the children ranged from 5 days to 14 years, with a mean age of 5 years. Infants ( $<2$ years) accounted for $42.72 \%$, preschool (2 - 5 years) $33.77 \%$, school age (6 - 11 years) $15.9 \%$ and adolescents ( 12 - 14 years) 7.61\%. There were slightly more female patient 157 (52\%) than male patient 145 (48\%) with a sex ratio of 0.9 . More than the third of the children consulted during the months of September and October.

\subsection{At the Clinical Level}

The two main reasons for consultation were pruritus $(22.65 \%)$ and papular lesions $(21.15 \%) .63 .2 \%$ of the children was admitted to the dermatology consultation by a family member and $15.9 \%$ by a pediatrician (Table 1 ). But more than the third of the children (39.07\%) have been previously consulted by a pediatrician. Among Children referred with a skin diagnosis, the half had a correct diagnosis. The duration of the diseases ranged from 1 day to 9 months with a mean of 2 months 20 days. In the study the diseases were classified in 8 cathégories. The most prevalent disorders by category were dermatitis (57.9\%) and infections (29.5\%); Followed by genodermatosis (7.2\%) and cutaneous tumors (6\%). Multiple diagnoses were made in $9.27 \%$ of the patients. The most common pathologies encountered were prurigo (23.2\%), scabies (12.9\%) and atopic dermatitis (9.6\%) (Table 2). Concerning the skin disorders in relation to gender and age groups, prurigo and atopic dermatitis involve equally females and males in the preschool age. But a predominance of females with scabies were seen (61.5\%). Impetigo (8.6\%), napkin dermatitis (5\%) and haemangioma (2.6\%) were most common in infancy. The lesions were mainly located on the head (23.31\%), the lower limbs (20.51\%) and the upper limbs (20.30\%). In almost all cases $(99.3 \%)$ the diagnosis was essentially clinical.

Table 1. Distribution according to the person who refers the patient.

\begin{tabular}{ccc}
\hline Dermatoses & Effective & Proportion \\
\hline Member of the familly & 191 & $63.2 \%$ \\
Pediatrician & 48 & $15.9 \%$ \\
Other Medial doctors & 27 & $8.9 \%$ \\
Dermatologist & 24 & $8 \%$ \\
Other health worker & 12 & $4 \%$ \\
Total & 302 & $100 \%$ \\
\hline
\end{tabular}


Table 2. Distribution according to the main dermatoses.

\begin{tabular}{ccc}
\hline Dermatosis & Effective & Proportion \\
\hline Prurigo & 70 & $23.2 \%$ \\
Scabies & 39 & $12.9 \%$ \\
Atopic Dermatitis & 29 & $9.6 \%$ \\
Seborrheic Dermatitis & 26 & $8.6 \%$ \\
Contact Eczema & 26 & $8.6 \%$ \\
Tinea & 16 & $5,3 \%$ \\
Impétigo & 15 & $5 \%$ \\
Molluscum contagiosum & 09 & $3 \%$ \\
\hline
\end{tabular}

\section{Discussion}

The spectrum of pediatric skin diseases in our study gives an insight into the diseases that are encountered in our country and highlights the diagnostic and management difficulties. Only 302 pediatric skin conditions were reported in 2 years with a prevalence of $2.6 \%$. This rate is lower than some data from west Africa [4]. This low percentage could be explained by the fact that the study focused only on the patients seen in pediatric dermatology consultation. In fact the children consulted in the service are not yet all referred in the unit of pediatric dermatology. The age of the children ranged from 5 days to 14 years, with a mean age of 5 years. This was also noted by Katibi and al [5]. This could be explained by the high vulnerability of patients at this age in terms of inflammatory and infectious dermatoses. More than the half of our patients were female. The female predominance were also noticed by Findlay and al and attributed to increasing concern which would be more worrying for the female children [6]. More than $1 / 3$ of the children consulted during the months of September and October. This period corresponds to the beginning of the school year with the high risk of interpersonal contamination. It is also the small rainy season, responsible for the proliferation of insects whose bites can give rise to certain dermatoses [7].

In our study, the main reason for consultation was pruritus $(22.65 \%)$ followed by papularlesions (21.15\%). Pruritus is the main symptom of many dermatoses. It gives some times insomnia and can impaire the quality of life [8]. Papular lesions have often a chronic course. Only $15.9 \%$ of the children were referred by a pediatrician whereas more than $1 / 3(39.07 \%)$ of the children had been previously consulted by a pediatrician. Skin diseases are usually referred to the dermatologist because of treatment difficulties or diagnostic dilemma [9].

Pathologies such as scabies and seborrheic dermatitis were often misdiagnosed in our study. These results invite to a better collaboration between pediatricians and dermatologists. The duration of the diseases ranged from 1 day to 9 months with a mean of 2 months 20 days. This long delay could be explained by self-medication and previous treatments not always adapted .This was also noted 
by Ogunbiyi and Shibeshi [4] [10] in Nigeria and Ethiopia. In our study, the lesions were preferentially localized to the head. Aesthetic concerns could most likely explain this situation. The prevalent disease categories were dermatitis (57.9\%) and infections (29.5\%) in our study. This pattern was also reported by Shibeshi [10] in Ethiopia, where allergic skin diseases accounted for $55.1 \%$, followed by the infections (32.8\%) and photodermatoses (8\%). Multiple diagnosis were made in $9.27 \%$ of the patients such as atopic dermatitis associated with warts or molluscum contagiosum. This should promptmedical practitioners to look out for other lesions on the skin apart from the presenting skin complaint. The most common pathologies encountered were prurigo (23.2\%), scabies (12.9\%) and atopic dermatitis (9.6\%). Prurigo and atopic dermatitis involve equally female and male in the preschool age but there were a predominance of females with scabies. The trend of Atopic dermatitis peaking in the preschool age and reducing significantly in adolescence is consistent with the fact that this condition improves with age [11]. Concerning scabies the predominance of girls in the pediatric population of Côte d'Ivoire and the increasing concern of skin damages for females can probably explain this prevalence. Environmental factors such as insect bites and parasitic infections play also a major rôle in the etiology of pediatric skin conditions. Thus Hogewoning and Kaliaperumal noted that infections were the highest in their studies from Ghana, Gabon and South India. They attributed it to poor hygiene, low socioeconomic levels and the prevalence of poor health awareness [12] [13].

\section{Conclusion}

In Côte d'Ivoire, pediatric dermatoses are numerous and varied. They are dominated by Prurigo, Scabiosis and atopic dermatitis. Their prevalence is still low in the pediatric dermatology unit. This study invites for close collaboration between pediatricians and dermatologists in order to optimize their therapeutic management. The knowledge of this spectrum of pediatric skin diseases would be useful for future health planning in order to reduce disease burden.

\section{Conflicts of Interest}

The authors declare no conflicts of interest regarding the publication of this paper.

\section{References}

[1] El-Khateeb, E.A., Lotfi, R.A., Abdel-Aziz, K.M. and El-Shiekl, S.E. (2014) Prevalence of Skin Diseases among Primary Schoolchildren in Damietta, Egypt. International Journal of Dermatology, 53, 609-616. https://doi.org/10.1111/ijd.12335

[2] Dagnatchew, S. (2000) Pattern of Skin Disease at the Ethio-Swedish Pediatric Hospital, Addis Ababa, Ethiopia. Pediatric Dermatology, 17, 357-359. https://doi.org/10.1046/j.1525-1470.2000.017005357.x

[3] Manisha, B., Ashok, K.K., Lalit, K.G., Asit, M. and Kuldeep, C.M. (2012) Pattern of Pediatric Dermatoses in a Tertiary Care Center of South West Rajasthan. Indian 
Journal of Dermatology, 57, 275-278. https://doi.org/10.4103/0019-5154.97665

[4] Ogunbiyi, A.O., Daramola, O.O. and Alese, O.O. (2004) Prevalence of Skin Diseases in Ibadan, Nigeria. International Journal of Dermatology, 43, 31-36. https://doi.org/10.1111/j.1365-4632.2004.01967.x

[5] Katibi, O.S., Dlova, N.C., Chateau, A.V. and Mosam, A. (2016) The Prevalence of Paediatric Skin Conditions at Adermatology Clinic in KwaZulu-Natal Province over a 3-Month Period. SAJCH, 10, 121-125. https://doi.org/10.7196/SAJCH.2016.v10i2.985

[6] Findlay, G.H., Vismer, H.F. and Sophianos, T. (1974) The Spectrum of Paediatric Dermatology. Analysis of10,000 Cases. British Journal of Dermatology, 91, 379-387. https://doi.org/10.1111/j.1365-2133.1974.tb13075.x

[7] Kabir, S., Supriya, M., Rashmi, S., Vibhu, M., Premanshu, B., Koranne, R.V., et al. (2009) The Spectrum of Skin Diseases among Indian Children. Pediatric Dermatology, 26, 6-13. https://doi.org/10.1111/j.1525-1470.2008.00814.x

[8] Bickers, D.R., Lim, H.W., Margolis, D., et al. (2006) The Burden of Skin Diseases: 2004: A Joint Project of the American Academy of Dermatology Association and the Society for Investigative Dermatology. Journal of the American Academy of Dermatology, 55, 490-500. https://doi.org/10.1016/j.jaad.2006.05.048

[9] Tamer, E., Ilhan, M.N., Muhterem, P., Nurdan, L. and Nuran, A. (2008) Prevalence of Skin Diseases among Pediatrics Patients in Turkey. Journal of Dermatology, 35, 413-418. https://doi.org/10.1111/j.1346-8138.2008.00495.x

[10] Shibeshi, D. (2000) Pattern of Skin Disease at the Ethio-Swedish Pediatric Hospital, Addis Ababa, Ethiopia. Pediatric Dermatology, 17, 357-359. https://doi.org/10.1046/j.1525-1470.2000.017005357.x

[11] Carroll, C.L., Balkrishnan, R., Feldman, S.R., et al. (2005) The Burden of Atopic Dermatitis: Impact on the Patient, Family, and Society. Pediatric Dermatology, 22, 192-199. https://doi.org/10.1111/j.1525-1470.2005.22303.x

[12] Hogewoning, A., Amoah, A., Bavinck, J.N.B., Boakye, D., Yazdanbakhsh, M. and Adegnika, A. (2013) Skin Diseases among Schoolchildren in Ghana, Gabon, and Rwanda. International Journal of Dermatology, 52, 589-600. https://doi.org/10.1111/j.1365-4632.2012.05822.x

[13] Kaliaperumal, K., Thappa, D.M. and Jeevankumar, B. (2004) Pattern of Pediatric Dermatosis in a Referral Center in South India. Indian Pediatrics, 41, 373-377. 